\title{
An uncommon presentation for a severe invasive infection due to methicillin-resistant Staphylococcus aureus clone USA300 in Italy: a
} case report Piero Valentini ${ }^{1}$, Gabriella Parisi ${ }^{2}$, Monica Monaco ${ }^{3}$, Francesca Crea ${ }^{1}$, Teresa Spanu ${ }^{4}$, Orazio Ranno ${ }^{1}$, Mirella Tronci ${ }^{2}$ and Annalisa Pantosti*3

Address: ${ }^{1}$ Istituto di Clinica Pediatrica, Università Cattolica del Sacro Cuore, Largo Agostino Gemelli 8, 00168 Rome, Italy, ${ }^{2}$ Dipartimento dei Servizi, Azienda Ospedaliera San Camillo Forlanini, Circonvallazione Gianicolense 87, 00152 Rome, Italy, ${ }^{3}$ Dipartimento di Malattie Infettive, Parassitarie ed Immunomediate, Istituto Superiore di Sanità, Viale Regina Elena 299, 00161 Rome, Italy and ${ }^{4}$ Istituto di Microbiologia, Università Cattolica del Sacro Cuore, Largo Agostino Gemelli 8, 00168 Rome, Italy

Email: Piero Valentini - pvalentini@rm.unicatt.it; Gabriella Parisi - gaparisi@scamilloforlanini.rm.it; Monica Monaco - monica.monaco@iss.it; Francesca Crea - francescacrea@email.it; Teresa Spanu - tspanu@rm.unicatt.it; Orazio Ranno - oranno@rm.unicatt.it; Mirella Tronci - mtronci@scamilloforlanini.rm.it; Annalisa Pantosti* - annalisa.pantosti@iss.it

* Corresponding author

\section{Published: 30 April 2008}

Annals of Clinical Microbiology and Antimicrobials 2008, 7:II doi:10.1 186/1476-07II-7II

This article is available from: http://www.ann-clinmicrob.com/content/7/I/II

(c) 2008 Valentini et al; licensee BioMed Central Ltd.

This is an Open Access article distributed under the terms of the Creative Commons Attribution License (http://creativecommons.org/licenses/by/2.0), which permits unrestricted use, distribution, and reproduction in any medium, provided the original work is properly cited.
Received: 5 February 2008

Accepted: 30 April 2008

\begin{abstract}
Background: Methicillin resistant Staphylococcus aureus (MRSA) has been considered for many years a typical nosocomial pathogen. Recently MRSA has emerged as a frequent cause of infections in the community. More commonly, community-acquired (CA)-MRSA is a cause of infections of the skin and soft-tissues, but life-threatening infections such as necrotizing pneumonia and sepsis can occasionally occur.
\end{abstract}

Case presentation: This report describes an uncommon presentation of invasive CA-MRSA infection in an adolescent without known risk factors. The presentation was typical for bacterial meningitis, but the clinical findings also revealed necrotizing pneumonia. Following the development of deep venous thrombosis, the presence of an inherited trombophilic defect (factor $V$ Leiden) was detected. The patient was successfully treated with an antibiotic combination including linezolid and with anticoagulant therapy. CA-MRSA was isolated from both cerebrospinal fluid and blood. The isolates were resistant to oxacillin and other beta-lactam antibiotics and susceptible to the other antibiotics tested including erythromycin. Molecular typing revealed that the strains contained the Panton-Valentine leukocidin genes and type IV SCCmec, and were ST8, spa type t008, and agr type I. This genetic background is identical to that of the USA 300 clone.

Conclusion: This report highlights that meningitis can be a new serious presentation of CA-MRSA infection. CA-MRSA strains with the genetic background of the USA300 clone are circulating in Italy and are able to cause severe infections. 


\section{Background}

Although considered a typical nosocomial pathogen for a long time, methicillin resistant Staphylococcus aureus (MRSA) has recently emerged as a cause of infections in the community. Most commonly, community-acquired (CA)-MRSA causes skin and soft-tissue infections [1,2] while severe and life-threatening infections such as necrotizing pneumonia [3], necrotizing fasciitis [4] and severe sepsis [5] represent rare cases. CA-MRSA strains are globally spread but their prevalence and distribution vary from country to country [6]. In the United States, CAMRSA isolates have become major community pathogens [1] and are starting to be introduced into the health-care system [7]. In that country, most of the recent CA-MRSA isolates belong to a single clone, that can be identified on the basis of Pulsed Field Gel Electrophoresis (PFGE) profile and other genotyping characteristics and is designed USA300 [2]. In Europe, the prevalence of infections due to CA-MRSA appears to be lower than in the United States, although recent reports highlight that these infections are on the rise. In a French hospital the incidence of skin and soft tissue infections due to CA-MRSA increased from $0 \%$ in 2000 to $6.8 \%$ in 2003 [8]. In Copenhagen the number of MRSA isolates, mainly obtained from communityacquired skin infections, doubled in less than 1 year, from 2003 to 2004) [9]. Differently from the situation in the United States where one clone predominates, CA-MRSA clones circulating in Europe are more diverse and heterogeneous [6].

In CA-MRSA isolates mec, the gene coding for methicillin resistance, is usually contained in the type IV variant of the genetic element staphylococcal chromosomal cassette (SCC)mec, that is smaller and probably more mobile than the other SCCmec elements [10]. CA-MRSA often contains the Panton-Valentine leukocidin (PVL), a toxin endowed with the unique ability to kill leukocytes [11]. PVL was initially associated with skin infections [12] and recently has been shown to play an essential role in the pathogenesis of necrotizing pneumonia [13].

We describe here an uncommon presentation of invasive CA-MRSA infection, with meningitis, bacteremia and necrotizing pneumonia in association with deep vein thrombosis, in a previously healthy adolescent.

\section{Case presentation}

A 15-year-old boy presented to the emergency department with a 4-day history of headache, fever, and lumbar pain and 1-day history of vomiting. His past clinical history was unremarkable, with the exception of mild asthma during childhood. Initial examination showed: temperature $40^{\circ} \mathrm{C}$, heart rate 120 beats $/ \mathrm{min}$, respiratory rate 30 breaths/min, blood pressure $120 / 78 \mathrm{mmHg}$, mild disorientation (Glasgow Coma Scale 14) and meningeal signs.
A small infiltrating skin lesion, partly crusted and partly purulent, was present on the back. The boy had been on a trekking vacation in Sicily and the lesion had been reportedly caused by the backpack on the bare skin. A chest radiogram showed bilateral multiple nodular infiltrates. Ultrasound examination of the abdomen revealed moderate enlargement of the liver and the spleen. A brain CT scan was normal. Analysis of blood samples at admission revealed a white blood cell count of 10,300 cells $/ \mathrm{mm}^{3}$ with $86 \%$ polymorphonuclear leukocytes. Arterial blood gas analysis showed moderate hypoxemia $\left(\mathrm{Pa}_{\mathrm{O} 2}\right.$ of $73 \mathrm{~mm}$ $\mathrm{Hg}$ on room air). Blood cultures and a lumbar puncture were performed. Cerebrospinal fluid (CSF) examination revealed several red blood cells and a leukocyte count of 600 cells/ml, a protein level of $392 \mathrm{mg} / \mathrm{dL}$, and a normal glucose level. Antibiotic therapy with clarithromycin and ceftriaxone was initiated and the patient was transferred to the Pediatric Intensive Care Unit (PICU) of another hospital, where his therapy was changed to ampicillin, doxicycline, ceftriaxone and acyclovir. Laboratories studies revealed a white blood cell count of 8,700 cells $/ \mathrm{mm}^{3}$ with $84.8 \%$ polymorphonuclear leukocytes, platelet $130,000 /$ $\mathrm{mm}^{3}$, C-reactive protein $187 \mathrm{mg} / \mathrm{l}$ (normal value $<3 \mathrm{mg}$ / l), prothrombin time $20.90 \mathrm{sec}$, activated partial thromboplastin time $42 \mathrm{sec}$, international normalized ratio 1.57, fibrinogen $1060 \mathrm{mg} / \mathrm{dL}$ (normal range 200-400 mg/ $\mathrm{dL}$ ), antithrombin III 39.8\% (normal range 70-120\%), D-dimer $>4500 \mathrm{ng} / \mathrm{ml}$ (normal value $<278 \mathrm{ng} / \mathrm{ml}$ ). The patient did not require mechanical ventilation and after 18 hours was discharged from the PICU and readmitted to the pediatric ward in stable conditions, conscious and still febrile to $40^{\circ} \mathrm{C}$. Blood and CSF cultures from admission grew MRSA. Ampicillin was discontinued and vancomycin was added. Since fever persisted unabated, on day 5 the antibiotic therapy was switched to teicoplanin (400 $\mathrm{mg}$ iv twice a day), linezolid (600 $\mathrm{mg}$ iv twice a day) and rifampicin (600 mg iv once a day). A heart ultrasound revealed no valvular vegetations. A CT scan showed bilateral lung cavitary lesions suggesting multiple abscesses, bilateral pleural effusion (Fig. 1), thrombosis of the inferior vena cava below the renal veins, and of both iliac veins. Low molecular weight heparin was started. The patient demonstrated gradual clinical improvement, with slow normalization of temperature and C-reactive protein concentration. CT scan showed reduction of the nodular lesions and of the pleural effusion. Abdomen CT scan and echo-colour Doppler revealed resolution of the venous thrombosis. The patient completed a 5-week course of teicoplanin, rifampicin, and linezolid and was discharged home at day 40 in good general conditions. Anticoagulation was continued for a total of 6 months.

Because of the unusual severity of the infection, underlying immunological or hematological defects were investigated. Quantitative immunoglobulins and subtypes, 


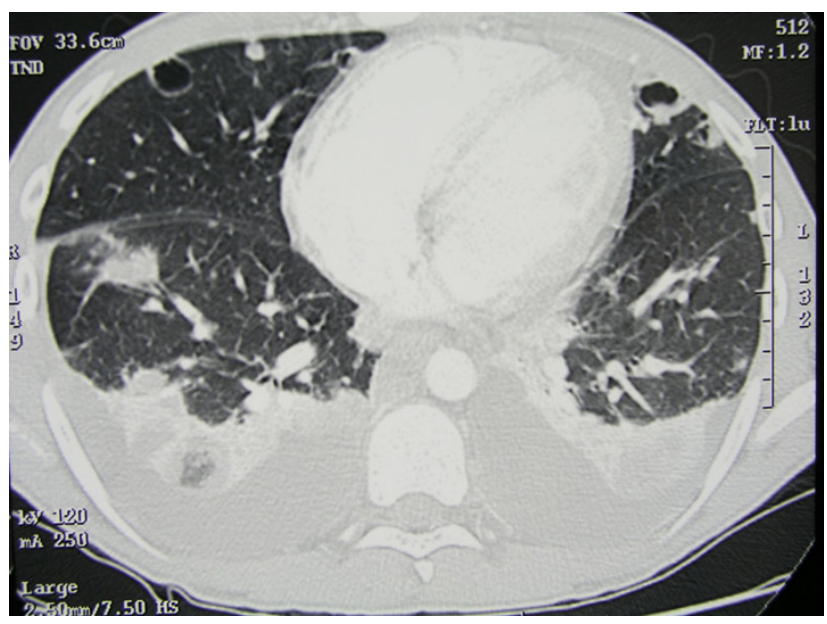

Figure I

Chest CT of a patient with necrotizing pneumonia caused by CA-MRSA USA300 genotype. The CT scan, obtained on hospital day 5 , shows multiple nodular lesions, some with a central cavitation, and bilateral pleural effusion.

lymphocyte subtypes, and phagocyte function were normal. The presence of heterozygous factor $\mathrm{V}$ Leiden and prothrombin gene mutation (G20210A) was revealed.

\section{Phenotypic and genotypic characterizations of MRSA}

$S$. aureus was identified by standard microbiological methods. Antibiotic susceptibility testing was performed by BD Phoenix ${ }^{\mathrm{TM}}$ Automated Microbiology System (Beckton Dickinson) and confirmed by E-test (AB Biodisk, Solna, Sweden). The species identification and the methicillin resistance status were confirmed by a duplex PCR targeting the genes nuc and mec [14]. MRSA grew from the blood and CSF cultures obtained at admission and from a second blood culture performed after $48 \mathrm{~h}$, before the institution of vancomycin therapy. The isolates were resistant to oxacillin but susceptible to non-beta-lactam antibiotics including erythromycin, clindamycin, ciprofloxacin, tetracycline, rifampicin, gentamicin, vancomycin, teicoplanin and linezolid. By E-test, the MIC for vancomycin was $2 \mu \mathrm{g} / \mathrm{ml}$. Further characterization of the isolates was obtained by PCR assays and included determination of the SCCmec type, agr group, and presence of the PVL genes lukS-PV and lukF-PV [14]. Genotyping of the strains was obtained by PFGE, Multilocus Sequence Typing and by sequencing the polymorphic region of protein A (spa typing) as previously described [14]. The isolates from blood and CSF were identical by PFGE, and carried SCCmec type IV and the genes coding for PVL. Molecular typing showed that the strains were spa type t008, ST8 and agr type 1, characteristics shared by the USA300 CA-MRSA clone.

\section{Conclusion}

The development of a serious infection in a young person without predisposing conditions is a typical feature of CAMRSA infections. However, to our knowledge, this is the first described case of CA-MRSA infection presenting with meningitis in an adolescent. The isolation of CA-MRSA from CSF is not common. CA-MRSA was isolated from the CSF of a 16-month-old child who died from fulminant sepsis. She had multiple abscesses in several organs, including the brain [15]. A case of CA-MRSA meningitis in an adult subject was mentioned in a study from HongKong, but apart from the unfavorable outcome, clinical data are lacking [16]. Another fatal case recently reported, was that of a woman with a history of furunculosis and drug addiction, who developed a brain abscess due to CAMRSA [17]. In our patient, meningeal symptoms were predominant at presentation, and the respiratory symptoms remained moderate in spite of the large involvement of the lungs as demonstrated by CT scan. The patient did not present airways hemorrhage, nor leukopenia, both factors being associated with fatal outcome in necrotizing pneumonia [18]. The skin infection on the patient's back might have represented the initial source for hematogenous spread of CA-MRSA, although microbiological examination of the purulent secretion was not performed.

Bacteremia due to typical CA-MRSA containing the PVL genes is rare but not exceptional, since typical CA-MRSA can be isolated from blood in the course of severe sepsis [5] or in other serious CA-MRSA infections in children and adolescents $[19,20]$. In an unselected patient population, bloodstream infections due to PVL-positive CAMRSA are very rare in Europe, as shown in a recent study from England [21] that included mainly isolates from elderly patients. In the USA, an increasing number of bloodstream infections in hospitalized patients is due to typical PVL-positive CA-MRSA [22], probably reflecting the introduction of the USA300 clone in the health-care setting in that country.

Another remarkable feature of this case is the association of the invasive CA-MRSA infection with deep venous thrombosis (DVT). DVT has been increasingly observed in children in association with osteomyelitis due to $S$. aureus containing the PVL genes [23]. Since the presence of PVL seems to be associated with greater systemic and local inflammation [20], it has been hypothesized that PVL could contribute substantially to the development of DVT. The expression "PVL syndrome" has been proposed to indicate a multifocal infection including osteomyelitis, skin infections, pneumonia, and DVT, due to PVL-positive S. aureus [24]. However, the association between PVL and DVT has been only observed in acute osteomyelitis and a causative role for PVL is unproven. In our patient, the CAMRSA infection has uncovered inherited trombophilic 
defects, the factor $\mathrm{V}$ Leiden and the prothrombin gene mutation, that have determined the development of DVT, with or without the contribution of PVL. On the other hand, the presence of heterozygous factor $\mathrm{V}$ Leiden is known to confer protection in the septic state and decrease sepsis-related mortality [25], therefore it can have contributed to the favorable outcome of this case.

The CA-MRSA strain involved had genotypic characteristic (agr type 1, ST8, t008) of the USA300 clone that has become the predominant CA-MRSA clone in the USA. In Europe, the most common clone is the "European clone", characterized by agr type 3 and ST80 [26], and typically resistant to fusidic acid [27]. Recently, strains with the USA300 genotype are starting to be isolated with increasing frequency in various European countries [6]. In Germany, CA-MRSA isolates with the characteristics of the USA300 clone have become the second most frequent, after the ST80 isolates [28]. In Italy, a strain with the genotyping characteristics of the USA300 clone was recently recognized as the cause of a serious skin infection in a child [29].

The empirical therapy started for meningitis and community acquired pneumonia in this patient, that included ceftriaxone and clarithromycin, is ineffective against MRSA. In addition, ceftriaxone and beta-lactam antibiotics in general have been shown to increase the expression of PVL by $S$. aureus [30], thus potentially worsening the disease. When the results of the antibiotic susceptibility tests were available, vancomycin was started. However, since the vancomycin MIC of the isolate was at the breakpoint for susceptibility $(2 \mu \mathrm{g} / \mathrm{ml})$ and the patient's condition remained critical, a different antibiotic combination including linezolid was started. Linezolid was chosen because of its high antistaphylococcal activity, and its excellent CSF and lung tissue penetration. As in the previously described case of necrotizing pneumonia [14], linezolid therapy likely contributed to the favorable resolution of the CA-MRSA infection.

The antibiotic treatment of this patient raises several questions and reflects the lack of evidence-based data to guide the choice for the treatment of serious CA-MRSA infections. Vancomycin was used as the first-line treatment since it is effective against MRSA, and has been widely used in the past. Although vancomycin penetration in CSF is low, concentrations of $6-11 \mu \mathrm{g} / \mathrm{ml}$ are usually reached with inflamed meninges [31] and vancomycin is currently recommended in the antibiotic combination for the empirical treatment of bacterial meningitis [32]. The patient had also pneumonia and it is known that the levels reached by vancomycin in the lung compartment can be variable and insufficient for a bactericidal effect [31]. Poor penetration into the infected sites was a particularly critical issue in this case, since the MIC for vancomycin of the isolates was $2 \mu \mathrm{g} / \mathrm{ml}$, that is still in the susceptibility range but close to the breakpoint. Clinical failures have been reported in serious infections due to MRSA with reduced susceptibility to vancomycin [33].

All the above conditions might have determined the lack of clinical improvement of the patient. Therefore, a new antibiotic combination was attempted, including teicoplanin, rifampicin and linezolid. Although there are few clinical studies relating to the use of teicoplanin in meningitis, in a rabbit model of MRSA meningitis the antibacterial activity of vancomycin and teicoplanin was shown to be similar [34]. Recent studies have shown the efficacy of linezolid in the treatment of patients with central nervous system infections [35] and pneumonia [36], its efficacy being at least equivalent and in some instances superior, to that of vancomycin. The drug combination was chosen based on the in vitro susceptibilities of the isolates but no adjunctive in vitro tests were performed to show whether the combination had synergistic, additive or antagonistic activity. There are no published clinical studies with this antibiotic combination to support the choice.

This case adds a new clinical presentation to CA-MRSA infections and highlights the problems encountered in the choice of the therapy of serious community-acquired infections in the CA-MRSA era.

\section{Competing interests}

The authors declare that they have no competing interests.

\section{Authors' contributions}

PV participated in the design of the study and helped drafting the manuscript. GP conceived of the study and performed the antibiotic susceptibility of the bacterial isolates. MM carried out the molecular typing of the isolates. FC collected and analyzed the clinical data of the patient. TS contributed to the identification and antibiotic susceptibility of the isolates. OR produced the hematological data of the patient and participated in the coordination of the study. MT participated in the design of the study. AP coordinated the study and drafted the manuscript. All authors read and approved the final manuscript.

\section{Consent}

Written informed consent was obtained from the patient's parent for publication of this case report and of the accompanying image. A copy of the written consent is available for review by the Editor-in-Chief of this journal.

\section{Acknowledgements}

This study was supported in part by a grant from the Italian Ministry of Education, Research and Technology (FIRB 2005). 


\section{References}

I. Moran GJ, Krishnadasan A, Gorwitz RJ, Fosheim GE, McDougal LK, Carey RB, Talan DA: Methicillin-resistant Staphylococcus aureus infections among patients in the emergency department. N Engl J Med 2006, 355(7):666-674.

2. King MD, Humphrey BJ, Wang YF, Kourbatova EV, Ray SM, Blumberg HM: Emergence of community-acquired methicillin-resistant Staphylococcus aureus USA $\mathbf{3 0 0}$ clone as the predominant cause of skin and soft-tissue infections. Ann Intern Med 2006, I 44(5):309-317.

3. Francis JS, Doherty MC, Lopatin U, Johnston CP, Sinha G, Ross T, Cai M, Hansel NN, Perl T, Ticehurst JR, Carroll K, Thomas DL, Nuermberger E, Bartlett JG: Severe community-onset pneumonia in healthy adults caused by methicillin-resistant Staphylococcus aureus carrying the Panton-Valentine leukocidin genes. Clin Infect Dis 2005, 40(I): 100-107.

4. Miller LG, Perdreau-Remington F, Rieg G, Mehdi S, Perlroth J, Bayer AS, Tang AW, Phung TO, Spellberg B: Necrotizing fasciitis caused by community-associated methicillin-resistant Staphylococcus aureus in Los Angeles. $N$ Engl $J$ Med 2005, 352(14): | 445-|453.

5. Gonzalez BE, Martinez-Aguilar G, Hulten KG, Hammerman WA Coss-Bu J, Avalos-Mishaan A, Mason EO Jr., Kaplan SL: Severe staphylococcal sepsis in adolescents in the era of communityacquired methicillin-resistant Staphylococcus aureus. Pediatrics 2005, I I 5(3):642-648.

6. Tristan A, Bes M, Meugnier H, Lina G, Bozdogan B, Courvalin P, Reverdy ME, Enright MC, Vandenesch F, Etienne J: Global distribution of Panton-Valentine leukocidin-positive methicillinresistant Staphylococcus aureus, 2006. Emerg Infect Dis 2007, I 3(4):594-600.

7. Seybold U, Kourbatova EV, Johnson JG, Halvosa SJ, Wang YF, King MD, Ray SM, Blumberg HM: Emergence of community-associated methicillin-resistant Staphylococcus aureus USA300 genotype as a major cause of health care-associated blood stream infections. Clin Infect Dis 2006, 42:647-656.

8. Del Giudice P, Blanc V, Durupt F, Bes M, Martinez JP, Counillon E, Lina G, Vandenesch F, Etienne J: Emergence of two populations of methicillin-resistant Staphylococcus aureus with distinct epidemiological, clinical and biological features, isolated from patients with community-acquired skin infections. $\mathrm{Br} J$ Dermatol 2006, I 54(I): I I8-I24.

9. Bartels MD, Boye K, Larsen AR, Skov R, Westh H: Rapid increase of genetically-diverse methicillin-resistant Staphylococcus aureus, Copenhagen, Denmark. Emerg Infect Dis 2007, 13:1533-1540.

10. Pantosti A, Sanchini A, Monaco M: Mechanisms of antibiotic resistance in Staphylococcus aureus. Future Microbiol 2007 2:323-334.

II. Boyle-Vavra S, Daum RS: Community-acquired methicillinresistant Staphylococcus aureus: the role of Panton-Valentine leukocidin. Lab Invest 2007, 87( I):3-9.

12. Yamasaki O, Kaneko J, Morizane S, Akiyama H, Arata J, Narita S, Chiba J, Kamio Y, Iwatsuki K: The association between Staphylococcus aureus strains carrying Panton-Valentine leukocidin genes and the development of deep-seated follicular infection. Clin Infect Dis 2005, 40(3):38I-385.

13. Labandeira-Rey M, Couzon F, Boisset S, Brown EL, Bes M, Benito Y, Barbu EM, Vazquez V, Hook M, Etienne J, Vandenesch F, Bowden MG: Staphylococcus aureus Panton Valentine leukocidin causes necrotizing pneumonia. Science 2007, 3 I 5: I I30- I I33.

14. Monaco M, Antonucci R, Palange P, Venditti M, Pantosti A: Methicillin-resistant Staphylococcus aureus necrotizing pneumonia. Emerg Infect Dis 2005, I I(10): I647-I648.

15. Centers for Disease Control and Prevention (CDC): Four pediatric deaths from community-acquired methicillin-resistant Staphylococcus aureus - Minnesota and North Dakota, I9971999. MMWR Morb Mortal Wkly Rep 1999, 48:707-7IO.

16. Ho PL, Cheung C, Mak GC, Tse CW, Ng TK, Cheung CH, Que TL, Lam R, Lai RW, Yung RW, Yuen KY: Molecular epidemiology and household transmission of community-associated methicillin-resistant Staphylococcus aureus in Hong Kong. Diagn Microbiol Infect Dis 2007, 57(2):|45-I5I.
17. Sifri CD, Park J, Helm GA, Stemper ME, Shukla SK: Fatal brain abscess due to community-associated methicillin-resistant Staphylococcus aureus strain USA300. Clin Infect Dis 2007, 45(9): el I3-7.

18. Gillet $Y$, Venhems P, Lina G, Bes M, Vandenesch F, Floret D, Etienne $\mathrm{J}$ : Factors predicting mortality in necrotizing communityacquired pneumonia caused by Panton-Valentine leukocidin. Clin Infect Dis 2007, 45:3I5-32I.

19. Adem PV, Montgomery CP, Husain AN, Koogler TK, Arangelovich V, Humilier M, Boyle-Vavra S, Daum RS: Staphylococcus aureus sepsis and the Waterhouse-Friderichsen syndrome in children. N Engl I Med 2005, 353( I 2): | 245-125|.

20. Bocchini CE, Hulten KG, Mason EO Jr., Gonzalez BE, Hammerman WA, Kaplan SL: Panton-Valentine leukocidin genes are associated with enhanced inflammatory response and local disease in acute hematogenous Staphylococcus aureus osteomyelitis in children. Pediatrics 2006, I I 7(2):433-440.

21. Ellington MJ, Hope R, Ganner M, Ganner M, East C, Brick G, Kearns AM: Is Panton-Valentine leucocidin associated with the pathogenesis of Staphylococcus aureus bacteraemia in the UK? J Antimicrob Chemother 2007, 60(2):402-405.

22. Popovich KJ, Weinstein RA, Hota B: Are community-associated methicillin-resistant Staphylococcus aureus (MRSA) strains replacing traditional nosocomial MRSA strains? Clin Infect Dis 2008, 46(6):787-794.

23. Gonzalez BE, Teruya J, Mahoney DH Jr., Hulten KG, Edwards R, Lamberth LB, Hammerman WA, Mason EO Jr., Kaplan SL: Venous thrombosis associated with staphylococcal osteomyelitis in children. Pediatrics 2006, I I 7(5):1673-1679.

24. Swaminathan A, Massasso D, Gotis-Graham I, Gosbell I: Fulminant methicillin-sensitive Staphylococcus aureus infection in a healthy adolescent, highlighting 'Panton-Valentine leucocidin syndrome'. Intern Med J 2006, 36:744-747.

25. Yan SB, Nelson DR: Effect of factor $\mathbf{V}$ Leiden polymorphism in severe sepsis and on treatment with recombinant human activated protein C. Crit Care Med 2004, 32(5 Suppl):S239-46.

26. Vandenesch F, Naimi T, Enright MC, Lina G, Nimmo GR, Heffernan $\mathrm{H}$, Liassine N, Bes M, Greenland T, Reverdy ME, Etienne J: Community-acquired methicillin-resistant Staphylococcus aureus carrying Panton-Valentine leukocidin genes: worldwide emergence. Emerg Infect Dis 2003, 9(8):978-984.

27. Witte W, Braulke C, Cuny C, Strommenger B, Werner G, Heuck D Jappe U, Wendt C, Linde HJ, Harmsen D: Emergence of methicillin-resistant Staphylococcus aureus with Panton-Valentine leukocidin genes in central Europe. Eur J Clin Microbiol Infect Dis 2005, 24(I): I-5.

28. Witte W, Strommenger B, Cuny C, Heuck D, Nuebel U: Methicillinresistant Staphylococcus aureus containing the Panton-Valentine leucocidin gene in Germany in 2005 and 2006. J Antimicrob Chemother 2007, 60(6): I 258-1263.

29. Tinelli M, Pantosti A, Lusardi C, Vimercati M, Monaco M: First detected case of community-acquired methicillin-resistant Staphylococcus aureus skin and soft tissue infection in Italy. Euro Surveill 2007, I 2(4):E0704 I 2 I

30. Dumitrescu O, Boisset S, Badiou C, Bes M, Benito Y, Reverdy ME, Vandenesch F, Etienne J, Lina G: Effect of antibiotics on Staphylococcus aureus producing Panton-Valentine leukocidin. Antimicrob Agents Chemother 2007, 5 I (4): I5 I5-1519.

31. Rybak MJ: The pharmacokinetic and pharmacodynamic properties of vancomycin. Clin Infect Dis 2006, 42 Suppl I :S35-9.

32. Tunkel AR, Hartman BJ, Kaplan SL, Kaufman BA, Roos KL, Scheld WM, Whitley RJ: Practice guidelines for the management of bacterial meningitis. Clin Infect Dis 2004, 39(9): | 267-| 284.

33. Howden BP, Ward PB, Charles PG, Korman TM, Fuller A du Cros P Grabsch EA, Roberts SA, Robson J, Read K, Bak N, Hurley J, Johnson PD, Morris AJ, Mayall BC, Grayson ML: Treatment outcomes for serious infections caused by methicillin-resistant Staphylococcus aureus with reduced vancomycin susceptibility. Clin Infect Dis 2004, 38(4):52I-528.

34. Sipahi OR, Arda B, Yurtseven T, Sipahi H, Ozgiray E, Suntur BM, Ulusoy $S$ : Vancomycin versus teicoplanin in the therapy of experimental methicillin-resistant Staphylococcus aureus (MRSA) meningitis. Int J Antimicrob Agents 2005, 26(5):4I2-4I5. 
35. Ntziora F, Falagas ME: Linezolid for the treatment of patients with central nervous system infection. Ann Pharmacother 2007, $4 I(2): 296-308$.

36. Kohno S, Yamaguchi K, Aikawa N, Sumiyama Y, Odagiri S, Aoki N, Niki Y, Watanabe S, Furue M, Ito T, Croos-Dabrera R, Tack KJ: Linezolid versus vancomycin for the treatment of infections caused by methicillin-resistant Staphylococcus aureus in Japan. J Antimicrob Chemother 2007, 60(6): 136I-1369.

Publish with Biomed Central and every scientist can read your work free of charge

"BioMed Central will be the most significant development for disseminating the results of biomedical research in our lifetime. " Sir Paul Nurse, Cancer Research UK

Your research papers will be:

- available free of charge to the entire biomedical community

- peer reviewed and published immediately upon acceptance

- cited in PubMed and archived on PubMed Central

- yours - you keep the copyright

Submit your manuscript here:

http://www.biomedcentral.com/info/publishing_adv.asp 